Egyptian Journal of Aquatic Biology \& Fisheries

Zoology Department, Faculty of Science,

Ain Shams University, Cairo, Egypt.

ISSN $1110-6131$

Vol. 24(1): 99 - 118 (2020)

www.ejabf.journals.ekb.eg

\title{
Raphidascaroides brasiliensis (Nematoda: Anisakidae) infection and Bioaccumulation of Polycyclic Aromatic Hydrocarbons in Gymnarchus niloticus (Cuvier, 1829) in Lekki Lagoon, Nigeria.
}

\author{
Patrick Isibor* $^{* 1}$, Akinsanya Bamidele ${ }^{2}$, Soyinka Olukolajo ${ }^{3}$, Kuton Pentho ${ }^{3}$, \\ Obe Atinuke $^{2}$ and Saliu Kayode ${ }^{2}$ \\ 1- Department of Biological Science, Covenant University, Ota, Ogun State, Nigeria \\ 2- Department of Zoology, University of Lagos, Nigeria \\ 3- Department of Marine Science, University of Lagos, Nigeria \\ Corresponding Author: patrickisibor007@yahoo.com
}

\section{ARTICLE INFO}

Article History:

Received: Sep. 3, 2019

Accepted: Dec. 27, 2019

Online: Jan. 2020

\section{Keywords:}

Gymnarchus niloticus

Raphidascaroides

brasilie

Bioaccumulation

Depuration

Lekki Lagoon

Hydrocarbons

Toxicity

\begin{abstract}
The study aimed at determining the ability of Raphidascaroides brasiliensis to depurate polycyclic aromatic hydrocarbons (PAHs) in its host, Gymnarchus niloticus. PAHs levels were determined in the water, sediments, intestine of Gymnarchus niloticus and its enteric parasites sampled at Lekki Lagoon, Nigeria. PAHs were determined using High Performance Liquid Chromatograph (HPLC) (Prominence Dual brand from HGE) equipped with a detector Shimadzu UV-Visible (UV-Vis Prominence SPD 20 A). The levels of superoxide dismutase (SOD), catalase (CAT), reduced glutathione $(\mathrm{GSH})$, lipid peroxidation (MDA) and bioaccumulation in the fish intestine, liver and parasites were assessed as biomarkers. Analyses were conducted equally for the infected and uninfected fishes. The sequence of accumulation in the environmental matrices was parasite > intestine > sediment $>$ water. The ratios of phenanthrene/anthracene, fluorene/pyerene and acenaphthene/fluorene in the sediment were 1.820 , 29.667 , and 4.33 respectively. The source indices (> 1.0) indicate a petrogenic source. The carcinogenic health risks posed by both the low and high molecular weight PAHs $(0.027$ and 0.476 respectively) were insignificant; hence the fish may not pose toxicological threats to the consumers. Higher levels of PAHs and biochemical biomarkers in the uninfected fish compared to the infected suggest the differences could be linked to depurative tendencies of Raphidascaroides brasiliensis which might have contributed to alleviation of the PAH burden in the host Gymnarchus niloticus. A study on significant depuration at minimal parasite intensity is warranted.
\end{abstract}

\section{INTRODUCTION}

Pollution of Lekki Lagoon with polycyclic aromatic hydrocarbons (PAHs) through accidental oil spillage, human discharge of petroleum by-products (petrogenic source), combustion of organic substances (pyrogenic source) was earlier reported by Doherty and Otitoloju (2016). Previous biomonitoring studies on the Lagoon linked the pollution to unregulated anthropogenic activities which resulted in poor water quality and devastating impacts on the biota (Amaeze, 2015; Akinsanya et $a l ., 2019)$. Previous literatures have also reported contamination of the sediment in 
the Lagoon with PAHs (Smith and Guentzel, 2010; Enuneku and Ilegomah, 2015; Akinsanya et al., 2019).

The bulk of the PAHs detected in these environmental media have been linked to the Petroleum Products Marketing Company Ltd. (PPMC). The oil company has the largest petroleum depot in Nigeria which is located at Atlas Cove depot ( $\mathrm{N} 06^{\circ} 25^{\prime}$ 39.1", E $\left.03^{\circ} 23^{\prime} 52.9^{\prime \prime}\right)$. PPMC has a large network of pipelines which distributes petroleum products around Nigeria. Previous literatures pointed out that oil spill occurs in the lagoon as a result of transportation, storage and distribution of the petroleum products (Anyakora et al., 2004; Adeyemi et al., 2009; Akinsanya et al., 2014; Akinsanya et al., 2015). Secondary causes of pollution in Lekki Lagoon are treated and untreated waste water from manufacturing industries and oil companies in the catchment area (Amaeze, 2015).

Despite perturbation of the aquatic habitat, the populace consumes the fishes (particularly Gymnarchus niloticus) from the lagoon. Sadly, fishes are capable of accumulating PAHs in their living cells to concentrations much higher than in water, sediment and micro flora in their ambiance (Robert et al., 2014). This owes to high biomagnification capacity of fish through trophic transfers, coupled with the lipophilic nature of PAHs (Lu et al., 1999; Twiss et al., 2000; Robert at al., 2014). Furthermore, PAHs are readily adsorbed on particulates which aid their precipitation (Stankovic et al., 2011; Isibor and Imoobe, 2017). The repository role of bottom sediments increases the likelihood of exposure of bottom dwellers such as $G$. niloticus. Studies have detected 14-315 ng/g PAH in demersal fish (Albert and Ravendra, 2000; Humason and Gadbois, 1982), 54- 2803 ng/g was detected in mollusk (Knutzen and Sortland, 1982), 52- $1600 \mathrm{ng} / \mathrm{g}$ in crustacean (Humason and Gadbois, 1982), and 284-4665 ng/g in algae (Knutzen and Sortland, 1982).

Bioaccumulation and biochemical biomarkers are tools that can detect and assess PAHs' production of free radicals which cause damage to cell components (Imlay, 2003). The biomarkers may provide useful indices which may indicate early detection of ecological and health risks (Pena-Llopis et al. 2003; Akinsanya et. al., 2014; Isibor, 2017; Meyerhoff, 1975; Morrow et .al., 1975; Akinsanya et al., 2015; Akinsanya et al., 2018).

G. niloticus is highly sought after in the local markets in Lagos, Nigeria, for its fascinating oily flesh and appealing flavour, hence priced as an exotic fish species of high economic value. However, susceptibility of the fish to exposure to contaminants and parasitic infections may be fostered by its diet which comprises of other fish groups, mainly the Clarias and the Cichlids (Ayoade et al., 2013).

Various literatures have reported synergistic effects of xenobiotics and parasites on fish hosts (Akinsanya et al., 2015; Akinsanya et al., 2016; De Denato et al., 2017). However, there is need to explore parasite's ability to sequester the toxicant loads in the host fish. We propose that the parasites of G. niloticus may serve as a buffer by mediating the depuration of PAHs in the host. Taking a cue from our previous study (Akinsanya et al., 2019) in which we demonstrated the depurative potentials of Weyonia acuminate on 4,4-DDT, endosulfan 1, aldrin, and heptachlor in Synodontis clarias. Biochemical and bioaccumulation indices of fish may be influenced by the prevalence of parasitic infections in the fish. The result might provide some formidable baseline data which may be an effective guideline in protection of the lagoon.

The study aimed on exploring the depurative potentials of enteric parasite on PAHs in Gymnarchus niloticus using bioaccumulation factors biochemical biomarkers as assessment tools. 


\section{MATERIALS AND METHODS}

\section{Description of study area}

The study was carried out on Lekki Lagoon in Lagos State, Nigeria. The lagoon lies between longitudes $4^{\circ} 00^{\prime}$ and $4^{\circ} 15^{\prime} \mathrm{E}$ and latitudes $6^{\circ} 25^{\prime}$ and $6^{\circ} 37^{\prime} \mathrm{N}$ (Fig. 1). It has a surface area of about $247 \mathrm{~km}^{2}$ with a maximum depth of $6.4 \mathrm{~m}$.

The vegetation around the lagoon is characterized by shrub and raphia palmsRaphiia sudanica, oil palms- Elaies guineensis and coconut palms Cocus nicifera. The lagoon experiences both dry and rainy seasons, typical of the southern part of Nigeria, which supports a major fishery.

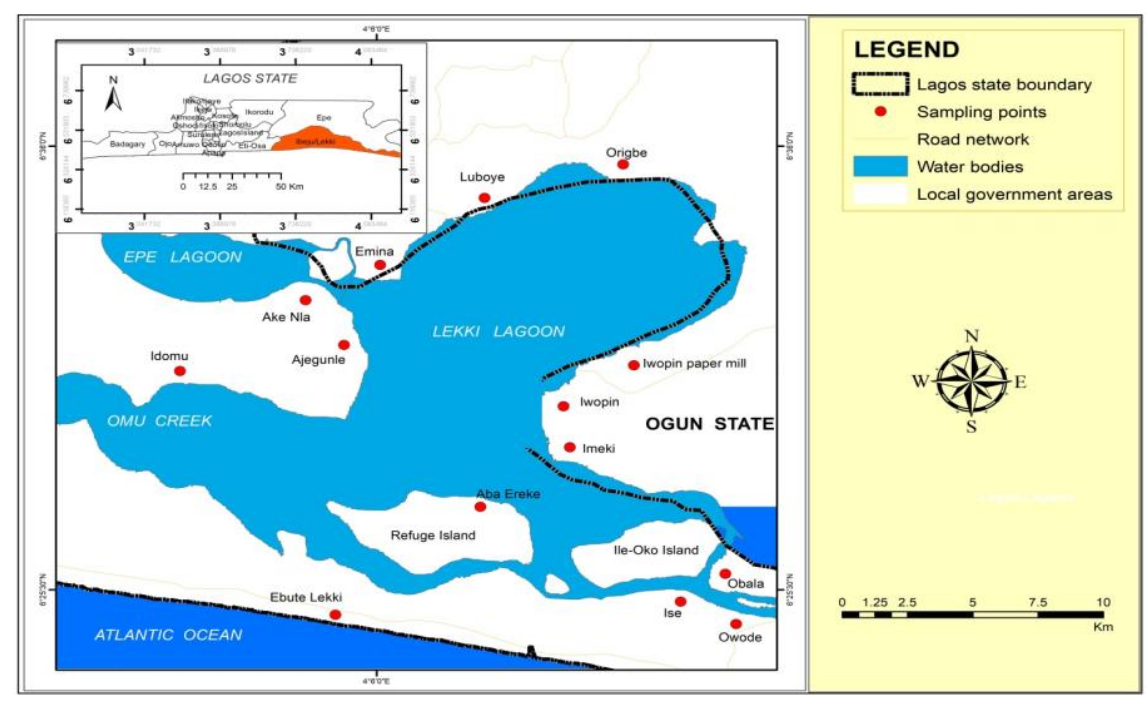

Fig. 1: A map of the study area

\section{Collection and examination of fish}

A total of 80 juvenile $G$. niloticus were captured randomly from Lekki Lagoon using gill nets (mesh sizes $50-55 \mathrm{~mm}$ ) within the periods of February 8-September 16, 2018. Some were collected with the help of fishermen and were transported in aerated plastic tanks to the laboratory of Zoology Department, University of Lagos, Nigeria.

The fish were sedated with $80 \%$ ethanol, euthanized and the intestines and livers excised with the aid of a sterile blade and kept in air-tight glass containers with lid. The containers were labeled appropriately according to sex and station. The labeled tissues were then preserved for 48 -h in a refrigerator at $-10{ }^{\circ} \mathrm{C}$ prior to further analysis.

\section{Morphometrics and sex determination}

Sex determination of the fish species was done by visual examination of the anal opening, presence or absence of eggs, and ovarian or testicular tissues (Robert and Yoshitaka, 2008). Age determination in the fish was carried by analyzing the annuli on the fish otoliths according to the technique described by Butler (1992). The weight of each fish specimen was measured to the nearest $0.01 \mathrm{~g}$ using a batterypowered digital Camry weighing balance (model EK-1A SERIES), while the standard length was measured using a metre rule. 


\section{Examination of fish parasites}

The abdominal cavity of each fish was cut open and the gastrointestinal parts were removed and cut into parts such as stomach, small intestine and large intestine using a sterile blade in a petri dish with normal saline for parasite collection. The parasites found were placed in a sample bottle containing $70 \%$ alcohol and numbers of parasites found in each specimen were recorded accordingly. Identification of parasite was done with the aid of identification manuals such as Colombo et al. (2005), Xing et al. (2005), and Sures (2007).

\section{Determination of PAHs in fish}

Extraction and analysis of PAHs in Gymnarchus niloticus were performed according to International Standard Organization (2004). A sample of $2.5 \mathrm{~g}$ of fish intestine or reference sample was introduced into a centrifuge tube and $10 \mathrm{~mL}$ of acetonitrile/acetone (V/V, 60/40) was added. Whole tissue was homogenized by vortexing $30 \mathrm{sec}$ and $5 \mathrm{~min}$ in ultrasonic bath before being centrifuged for $5 \mathrm{~min}$ at $4000 \mathrm{rpm}$. The supernatant was then removed and transferred into a conical tube and the solvent was heated at $35^{\circ} \mathrm{C}$ for $5 \mathrm{~min}$. The extraction was repeated twice with 10 $\mathrm{mL}$ of acetonitrile/acetone. The extract was then purified on the cartridges of bonded phase C18 (Waters Sep Pack). Purification was done by adding $2 \mathrm{~mL}$ of acetonitrile/acetone into a conical tube containing the sample. The mixture was vortexed for $15 \mathrm{sec}$ and centrifuged for $30 \mathrm{sec}$. The upper phase was transferred into a tube and the operation was repeated twice. The supernatants were transferred onto a C18 cartridge previously conditioned with $12 \mathrm{~mL}$ of methanol and $12 \mathrm{~mL}$ of acetonitrile. The elution was performed with $5 \mathrm{~mL}$ of acetonitrile/acetone at atmospheric pressure. The eluent was thereafter concentrated to $50 \mathrm{mg}$ using a rotary evaporator at $35^{\circ} \mathrm{C}$. The purified extract was recovered in $1 \mathrm{~mL}$ of hexane. The tube was crimped and stored at $-18^{\circ} \mathrm{C}$ before analysis.

PAHs were determined using a High Performance Liquid Chromatograph (HPLC) (Prominence Dual brand from HGE) equipped with a detector Shimadzu UV-Visible (UV-Vis Prominence SPD 20 A), a pump (LC 20AD Prominence Chromatograph), an automatic injector (Auto sampler Prominence SIL 20AC) and a column (Column Prominence Owen CTO 20A) type Prevail C18 (15 x 4.6 mm x 5 microns). The cartridge temperature was $40^{\circ} \mathrm{C}$, flow rate was $1 \mathrm{~mL} / \mathrm{min}$ and at wavelength of $254 \mathrm{~nm}$ (Ake et al., 2012).

\section{Analysis of biochemical biomarkers}

Thawed intestine tissues were homogenized in a buffer of $\mathrm{pH}-7.4$. The sample was centrifuged at $10,000 \mathrm{~g}$ for $20 \mathrm{~min}$ at $40^{\circ} \mathrm{C}$. Derived supernatant was drained and the pellet was rinsed with $7.4 \mathrm{pH}$ buffer and preserved in Eppendorf tube at $-85^{\circ} \mathrm{C}$ for 48-h prior to enzymatic assays (Siroka et al., 2005).

\section{Determination of superoxide dismutase (SOD) activity}

The SOD activity was measured by its ability to inhibit the anti-oxidative potential of epinephrine (that is determining the difference in the level of superoxide anion production and decomposition) at an absorbance of $450 \mathrm{~nm}$ using the method of Sun and Zigma (1978). The concentration of SOD was expressed as unit/mg protein. A unit was defined as the amount of enzymes needed to inhibit 50\% epinephrine per min and per mg of protein at $25^{\circ} \mathrm{C}$ and $\mathrm{pH} 7.8$. 


\section{Determination of catalase (CAT) activity}

CAT was assayed calorimetrically at $620 \mathrm{~nm}$ and expressed as moles of hydrogen peroxide $\left(\mathrm{H}_{2} \mathrm{O}_{2}\right)$ which consumed/min/mg protein as described by Quinlan et al. (1994). The reaction mixture $(1.5 \mathrm{~mL})$ contained $1.0 \mathrm{~mL}$ of $0.01 \mathrm{M} \mathrm{pH} 7.0$ phosphate buffer, $0.1 \mathrm{~mL}$ of plasma and $0.4 \mathrm{~mL}$ of $2 \mathrm{M} \mathrm{H}_{2} \mathrm{O}_{2}$. The reaction was stopped by the addition of $2.0 \mathrm{~mL}$ of dichromate-acetic acid reagent (5\% potassium dichromate and glacial acetic acid were mixed in 1:3 ratio).

\section{Determination of reduced glutathione (GSH)}

Reduced glutathione (GSH) was determined by the method of Ellman (1959). We added $10 \%$ of TCA to the earlier prepared homogenate and centrifuged at room temperature for $10 \mathrm{~min}$ at $3,000 \mathrm{rpm}$. We then treated $1.0 \mathrm{~mL}$ of supernatant with 0.5 $\mathrm{mL}$ of Ellmans reagent (19.8 mg of 5, 5'-dithiobisnitro benzoic acid (DTNB) in 100 $\mathrm{mL}$ of $0.1 \%$ sodium nitrate) and $3.0 \mathrm{~mL}$ of phosphate buffer $(0.2 \mathrm{M}, \mathrm{pH} 8.0)$. The absorbance was then read at $412 \mathrm{~nm}$.

\section{Determination of lipid peroxidation}

Malondialdehyde (MDA) was considered an index of lipid peroxidation. It was determined using the method of Buege and Aust (1978). 10mL of the supernatant was added to the $2 \mathrm{~mL}$ of (1:1:1 ratio) TCA-TBA-HCl reagent (thiobarbituric acid $0.37 \%$, $0.24 \mathrm{~N} \mathrm{HCl}$ and $15 \%$ TCA- trichloroacetic acid-thiobarbituric acid-hydrochloric acid). Mixture was boiled at $100{ }^{0} \mathrm{C}$ for $15 \mathrm{~min}$, and allowed to cool. Flocculent materials were removed by centrifuging at $3000 \mathrm{rpm}$ for $10 \mathrm{~min}$. The supernatant was removed and the absorbance read at $532 \mathrm{~nm}$ against a blank. MDA was calculated using the molar extinction coefficient for MDATBA- complex of $1.56 \times 10^{5} \mathrm{M}^{-1} \mathrm{CM}^{-1}$. $\mathrm{MDA}=\mathrm{A} \times \mathrm{V}_{\mathrm{T}} / \sum \mathrm{x} \mathrm{V}_{\mathrm{S}}$ $\mathrm{A}=$ Absorbance, $\mathrm{V}_{\mathrm{T}}=$ Total volume, $\mathrm{V}_{\mathrm{s}}=$ sample volume, $\sum=$ molar extinction.

\section{Collection and analysis of water samples}

Water samples were collected from 3 different locations in Epe axis of Lekki Lagoon using clean $1 \mathrm{~L}$ sampling bottles. The samples were kept in flasks lagged with ice packs and transported to the laboratory of the Department of Marine Sciences, University of Lagos, where they were further refrigerated at $4^{\circ} \mathrm{C}$ prior to laboratory analysis.

PAH standards of the EPA 610 mixture and a single standard of benzo [e] pyrene were obtained from SUPELCO (Mercks, Nigeria). We prepared the stock solution by mixing $0.9 \mathrm{~mL}$ EPA $610 \mathrm{mix}$ together with $0.1 \mathrm{~mL} 1.25 \mathrm{mg} / \mathrm{mL}$ benzo (e) pyrene. The calibration standards were prepared through dilution of the stock solution with acetonitrile. Five points were used to make the calibration curve.

Analysis of the trace levels of PAHs in water was carried out by extracting $1 \mathrm{~L}$ of water sample using an AccuBond ODS C18 SPE cartridge (Agilent p/n 188-1356). The cartridge $(0.5 \mathrm{~g})$ was conditioned by sequentially rinsing with four $10 \mathrm{~mL}$ aliquots of dichloromethane (DCM), methanol, and two 10-mL aliquots of water (HPLC grade). We then passed 1L water sample through the SPE cartridge at a flow rate of $2.5 \mathrm{~mL} / \mathrm{min}$ using an automated solid phase extractor. Afterwards, we washed the cartridge with $10 \mathrm{~mL}$ of HPLC water. The SPE cartridge was then dried by drawing nitrogen for about $10 \mathrm{~min}$. PAH sample was eluted from the cartridge with $5 \mathrm{~mL}$ DCM twice and added together. We then evaporated the elute with a stream of nitrogen to a volume of $1 \mathrm{~mL}$, and $3.0 \mathrm{~mL}$ of acetonitrile was added, which was 
concentrated to a final volume of $1.0 \mathrm{~mL}$ (USEPA, 1990). PAH concentration was then determined using a High Performance Liquid Chromatograph (HPLC).

\section{Collection and analysis of sediment samples}

Sediments were collected with the aid of Van Veen grab $(15 \times 15 \times 12 \mathrm{~cm})$ at each location and were stored immediately in polythene bags prior to analysis.

Soil sample was air-dried at room temperature for 48-h and passed through a sieve of mesh size $1 \mathrm{~mm}$. Afterwards, $10 \mathrm{~g}$ of the prepared soil samples weighed into a test tube. Then $10 \mathrm{~mL}$ of methanol was then added to extract PAH residue from the soil sample. The subsequent steps then followed the same procedures of the analysis of PAHs in the water samples.

\section{Quality control and quality assurance measures}

The adopted method of quantification of PAHs was validated using reference guidelines provided by Ake (2012) and the readings of HPLC were verified by the certificate provided by Association French De Normalization (1998). To ensure accuracy of equipment a study of the linearity of the calibration range was conducted.

The limits of detection and quantification were determined and the coefficient of variation for the tests was calculated for assurance of repeatability and reproducibility. The calculation of the percentage recovery for accuracy test was also conducted.

The linearity was tested between 0 and $10 \mu \mathrm{g} / \mathrm{L}$ using 5 points calibration $(0$ $\mu \mathrm{g} / \mathrm{L}, 2.5 \mu \mathrm{g} / \mathrm{L}, 5 \mu \mathrm{g} / \mathrm{L}, 7.5 \mu \mathrm{g} / \mathrm{L}$ and $10 \mu \mathrm{g} / \mathrm{L}$ ) for each of the PAH congeners. Ten (10) separate tests were repeatedly performed for each compound.

The limits of detection (LD) and limits of quantification (LQ) were calculated from the blank and analyzed by the HPLC.

Limit of detection was calculated with 3 separate trial thus;

$\mathrm{LD}=\mathrm{mb}+3 \mathrm{SD}$

While limit of quantification was calculated with 10 separate trials thus;

$\mathrm{LQ}=\mathrm{mb}+10 \mathrm{SD}$

Where $\mathrm{mb}=$ average concentration with the blank and $\mathrm{SD}=$ standard deviation of blank values.

\section{Statistical analysis}

\section{Bioaccumulation factor (BAF)}

Bioaccumulation factor (BAF) was calculated thus;

$B A F=\frac{C f}{C W}$

Where $\mathrm{Cf}$ represents the concentration of $\mathrm{PAH}$ congeners in fish, and $\mathrm{Cw}$ is concentration of the PAHs in the water sample at the same location.

While, the biota-sediment accumulation factor (BSAF) was calculated thus;

BSAF was calculated as:

$B S A F=\frac{C f}{C s}$

Where $\mathrm{Cf}$ is concentration of PAH congeners in fish and $\mathrm{Cs}$ is concentration of the PAHs in the sediment from the same zone.

\section{Risk assessment}


Risks of PAHs were calculated based on the two categories of the congeners; low molecular weight (LMW) PAHs (2-3 rings), and high molecular weight (HMW) PAHs (4-6 rings).

\section{Risk estimations for LMW PAHs (2- 3 rings)}

The carcinogenic health risks index (HRI) of LMW PAHs was determined using the mean intestinal concentration $(6.27 \mathrm{ng} / \mathrm{g})$ as follows;

$H R I=\frac{C x I R x E F x E D}{B W x A T} \times S F \times A D A F$ (IARC, 1983; NRC, 1983)

$H R I=\frac{6.27 \times 48 \times 52.62}{60 \times 365 \times 52.62} \times 2 \times 1$

$H R I=\frac{15836.52}{1152378} \times 2$

HRI of LMW PAHs $=0.027$

The ecological risk was calculated using FEPA (2003) limit of $2 \mathrm{ng} / \mathrm{L}$ for PAH and the mean concentration in water (Table 3) thus;

Ecological risk quotient $(E R Q)=\frac{\text { Environmental concentration }}{\text { Recommended limit }}$

$$
E R Q=\frac{0.287}{2}=0.14
$$

ERQ was below 1, hence estimated as not a significant ecological risk.

The adsorption coefficient (Ac) of LMW PAHs was calculated with the ratio of the mean concentration of PAH in water and the sediment (Table 3) thus;

$A c=\frac{C s}{C w}=\frac{0.38}{0.287}=1.1$

The Ac value being higher than 1, indicates a significant adsorption of the LMW PAHs into the sediment.

\section{Risk estimations for HMW PAHs (4-6 rings)}

The carcinogenic health risks index (HRI) of HMW PAHs was estimated using the mean intestinal concentration $108.67 \mathrm{ng} / \mathrm{g}$ as follows;

$$
\begin{gathered}
H R I=\frac{C \times I R \times E F \times E D}{B W \times A T} \times S F \times A D A F(\text { IARC, 1983; NRC, 1983) } \\
H R I=\frac{108.67 \times 48 \times 52.62}{60 \times 365 \times 52.62} \times 2 \times 1 \\
H R I=\frac{274474.34}{1152378} \times 2
\end{gathered}
$$

HRI of LMW PAHs $=0.476$

The ecological risk was calculated using FEPA (2003) limit of 2 ng/L for PAH and the mean concentration in water (Table 3 ) thus;

Ecological risk quotient $(E R Q)=\frac{\text { Environmental concentration }}{\text { Recommended limit }}$ 


$$
E R Q=\frac{0.266}{2}=0.133
$$

ERQ was below 1, hence estimated as not a significant ecological risk.

The adsorption coefficient (Ac) of HMW PAHs was calculated with the ratio of the mean concentration of PAH in water and the sediment (Table 3) thus;

Adsorption coefficient $(\mathrm{Ac})=\underline{\mathrm{Cs}}$

Where $\mathrm{Cs}=$ concentration adsorbed on soil, while $\mathrm{Cw}=$ concentration in water.

$A c=\frac{C s}{C w}=\frac{0.672}{0.266}=2.53$

The Ac value being much greater than 1 was considered a highly significant adsorption of the HMW PAHs into the sediment.

The study data was presented as descriptive statistics (mean \pm SD) which were subjected to analysis of variance (ANOVA), and Duncan Multiple Range tests. Thelinear regression and correlation coefficients were analyzed =using the Microsoft Excel 2007 and SPSS version 21. All the statistical analyses were considered at significance level of $\mathrm{p} \leq 0.05$.

\section{RESULTS}

\section{Fish morphometrics and parasite indices}

Nematode was detected in the gut of the fish which was identified as Raphidascaroides nipponensis. Gymnarchus niloticus fish inspected were 76 males and 4 females. Of the males, $7.89 \%$ were infected, while $25 \%$ of the females were infected with the gastrointestinal helminth parasites. The total parasite prevalence was $8.75 \%$ (Table 1 ).

Table 1: Gastrointestinal helminth infections in relation to sex of Gymnarchus niloticus

\begin{tabular}{llll}
\hline Samples & Male & Female & Total \\
\hline No. Examined & 76 & 4.0 & 80.0 \\
No. Infected & 6 & 1.0 & 7.0 \\
Infection $(\%)$ & 7.89 & 25.0 & 8.75 \\
\hline
\end{tabular}

The length group 41-60 $\mathrm{cm}$ had the highest prevalence of gastrointestinal helminth infection (12.50\%) while the length groups, $81-100 \mathrm{~cm}$ and 101-120 had no infection. An inverse relationship occurred between the standard length of the fish and parasitic prevalence (Table 2). While the weight group $0.0-0.5 \mathrm{~kg}$ had the highest prevalence of the gastrointestinal helminth infection (16.67\%). Groups 1-5-2.0, 2.02.5, and 2.5-3.0 kg had no infection (Table 3 ).

Table 2: Gastrointestinal helminth infections in relation to lenght of Gymnarchus niloticus

\begin{tabular}{llllll}
\hline Length $(\mathrm{cm})$ & $41-60$ & $61-80$ & $81-100$ & $101-120$ & Total \\
\hline No. Examined & 40.0 & 26.0 & 10.0 & 4.0 & 80.0 \\
No. Infected & 5.0 & 2.0 & 0.0 & 0.0 & 7.0 \\
Infection $(\%)$ & 12.50 & 7.69 & 0.0 & 0.0 & 8.75 \\
\hline
\end{tabular}

\section{Inter-media partitioning of PAHs}

High variability occurred in the distribution of PAHs in the water, sediment and biota from Lekki Lagoon (Table 2). The sequence of total PAHs among the environmental matrices was parasite> intestine> sediment> water. Among the low molecular weight (LMW) PAHs, ACP $(0.286 \mathrm{ng} / \mathrm{g})$ had the highest concentration in the water while NAP $(0.198 \mathrm{ng} / \mathrm{g})$ had the lowest concentration. In the bottom 
sediment, LMW PAH with the highest concentration was NAP $(0.413 \mathrm{ng} / \mathrm{g})$, while the lowest was ACP (0.216).

Total LMW PAHs detected in the sediment $(1.592 \mathrm{ng} / \mathrm{g})$ was higher than the level detected in the water $(0.287 \mathrm{ng} / \mathrm{g})$. The trend of LMW PAHs in the water was ACE $>$ ACP $>$ FL $>$ PHE $>$ NAP>, while the trend in the sediment was NAP> PHE> FL $>$ ACE $>$ ACP.

On the other hand, among the high molecular weight (HMW) PAHs, PYR, $\mathrm{B}(\mathrm{b}) \mathrm{FLU}$, and DiB(a)ANT had the lowest concentrations in the water, while B(ghi)PYL was the most predominant in the water. The HMW PAHs with low concentrations in the sediment were B(j)FLU and DiB(ah)PYR, while the one with the outstandingly higher concentrqtion was IN(cd)PYR. The sediment also had significantly higher mean $(0.672 \mathrm{ng} / \mathrm{g})$ and total $(12.094 \mathrm{ng} / \mathrm{g})$ HMW PAHs than the water which were $0.266 \mathrm{ng} / \mathrm{g}$ and $4.781 \mathrm{ng} / \mathrm{g}$ respectively.

High bioaccumulation factors and biota-sediment accumulation factors of a number of the PAHs were detected in the intestine of the fish. Among the LMW PAHs, NAP only was poorly bioaccumulated from the sediment into the intestine of the fish. However, appreciably high amount was accumulated from the water. The bioaccumulation from water to intestine (BAFi/w) of NAP, FL, and PHE were higher than their biota-sediment accumulation factors (BSAFi/s). The reverse was however the case for ACP and ACE. Results indicate significant levels of lipophilic tendencies in all the low molecular weight (LMW) PAHs. The parasites showed significant bioaccumulation of the LMW PAHs from the intestine of the fish.

The bioaccumulation of PAHs in the parasite matched the bioaccumulation in the intestine of G. niloticus from the water and sediment, except in ACE which was poorly bioaccumulated by the parasite. PHE was absorbed the most into the parasite.

Outstandingly high bioaccumulation factors and biota-sediment accumulation factors were detected in most of the high molecular weight (HMW) PAHs. This suggests that the HMW PAHs are more lipophilic than the LMW counterparts. Extremely high BAFi/w occurred in B(c)PHE $(4,086)$, followed by B(a)ANT $(3,637.88)>$ CHY (1497.16)> ANT (736.68)> B(k)FLU (616.46)> B(e)PYR (518.23)> B(j)FLU (344.79)> FLU (313.52)> B(a)PYR (255.49)> DiB(ai)PYR (8.25)> DiB(ah)PYR (2.88). Others have no significant BAFi/w.

From the bottom sediment, extremely high BSAFi/s was recorded for most of the HMW PAH congeners, i.e. B(c)PHE $(12,498.8)>$ B(a)ANT $(11,127.6)>$ PYR (4, 767.50)> B(k)FLU (1,945.15)> FLU (1, 382.86)except in B(j)FLU, IN(cd)PYR, and $\mathrm{DiB}(\mathrm{ah}) \mathrm{PYR}$ which were poorly accumulated from the sediment into the fish intestine. Outstandingly high HMW PAH congeners such as B(c)PHE $(12,498.8)>$ B(a)ANT (11,127.6)> PYR (4,767.50)> B(k)FLU (1,945.15)> FLU (1,382.86)> B(b)FLU (935.63)> ANT (587.70)> B(a)PYR (347.24)> DiB(a)ANT (96.79)> MChl (26.35)> DiB(ai)PYR (14.11)> B(ghi)PYL (2.35)> Di(ah)ANT (1.74). Others were not significantly accumulated from the soil into the intestine of the fish. The outstandingly high lipophilicities of LMW PAHs observed in the fish were quite matched by the significantly high BAFp/i indices of NAP, ACP, FL, and PHE; except in the case of ACE. The outstandingly high lipophilicities of HMW PAHs observed in the fish were also matched by the significantly high BAFp/i indices of ANT, FLU, PYR, B (c) PHE, CHY, B (k) FLU, B (a) PYR, B (b) FLU, MChl, and DiB(ai)PYR in the parasite. B (a) ANT, B (e) PYR, B(j)FLU, DiB(a)ANT, Di (ah) ANT, B (ghi) PYL and DiB (ah) PYR were though highly accumulated into the fish intestine, were however poorly depurated by the parasite. 
IN(cd)PYR concentrations were low in all tested media, except in the sediment where fairly high level was detected.

Table 3: Bioaccumulation factor (BAF) of PAH congeners in the fish intestine and parasite relative to the water and sediment

\begin{tabular}{lllllllll}
\hline $\begin{array}{l}\text { Types } \\
\text { of PAH }\end{array}$ & Congeners & Water & Sediment & Intestine & Parasite & BAFi/w & BSAFi/s & BAFp/i \\
\hline $2-3$ & NAP & 0.198 & 0.413 & 0.41 & 1.33 & $\mathbf{2 . 0 7}$ & 0.99 & $\mathbf{3 . 2 4}$ \\
Rings & ACP & 0.286 & 0.216 & 0.54 & 1.40 & $\mathbf{1 . 8 9}$ & $\mathbf{2 . 5 0}$ & $\mathbf{2 . 5 9}$ \\
& ACE & 0.512 & 0.243 & 0.59 & 0.25 & $\mathbf{1 . 1 5}$ & $\mathbf{2 . 4 3}$ & 0.42 \\
& FL & 0.231 & 0.356 & 20.92 & 49.58 & $\mathbf{9 0 . 5 6}$ & $\mathbf{5 8 . 7 6}$ & $\mathbf{2 . 3 7}$ \\
& PHE & 0.206 & 0.364 & 8.88 & 53.31 & $\mathbf{4 3 . 1 1}$ & $\mathbf{2 4 . 4 0}$ & $\mathbf{6 . 0 0}$ \\
& SUM & 1.433 & 1.592 & 31.34 & 105.87 & - & - & - \\
Rings 6 & MEAN & 0.287 & 0.318 & 6.27 & 21.17 & - & - & $\mathbf{2 0}$ \\
& ANT & 0.241 & 0.200 & 177.54 & 378.43 & $\mathbf{7 3 6 . 6 8}$ & $\mathbf{5 8 7 . 7 0}$ & $\mathbf{2 . 1 3}$ \\
& FLU & 0.247 & 0.056 & 77.44 & 257.25 & $\mathbf{3 1 3 . 5 2}$ & $\mathbf{1 3 8 2 . 8 6}$ & $\mathbf{3 . 3 2}$ \\
& PYR & 0.000 & 0.012 & 57.21 & 94.54 & 0.00 & $\mathbf{4 7 6 7 . 5 0}$ & $\mathbf{1 . 6 5}$ \\
& B(c)PHE & 0.052 & 0.017 & 212.48 & 406.73 & $\mathbf{4 0 8 6}$ & $\mathbf{1 2 4 9 8 . 8}$ & $\mathbf{1 . 9 1}$ \\
& B(a)ANT & 0.052 & 0.017 & 189.17 & 31.58 & $\mathbf{3 6 3 7 . 8 8}$ & $\mathbf{1 1 1 2 7 . 6}$ & 0.17 \\
& CHY & 0.243 & 0.287 & 363.81 & 626.45 & $\mathbf{1 4 9 7 . 1 6}$ & $\mathbf{1 2 6 7 . 6 3}$ & $\mathbf{1 . 7 2}$ \\
& B(k)FLU & 0.325 & 0.103 & 200.35 & 219.49 & $\mathbf{6 1 6 . 4 6}$ & $\mathbf{1 9 4 5 . 1 5}$ & $\mathbf{1 . 1 0}$ \\
& B(a)PYR & 0.492 & 0.362 & 125.70 & 329.25 & $\mathbf{2 5 5 . 4 9}$ & $\mathbf{3 4 7 . 2 4}$ & $\mathbf{2 . 6 2}$ \\
& B(e)PYR & 0.062 & 0.249 & 32.13 & 28.46 & $\mathbf{5 1 8 . 2 3}$ & $\mathbf{1 2 9 . 0 4}$ & 0.89 \\
& B(b)FLU & 0.000 & 0.359 & 335.89 & 345.22 & 0.00 & $\mathbf{9 3 5 . 6 3}$ & $\mathbf{1 . 0 3}$ \\
& B(j)FLU & 0.466 & 0.000 & 160.67 & 154.03 & $\mathbf{3 4 4 . 7 9}$ & 0.00 & 0.96 \\
& DiB(a)ANT & 0.000 & 0.112 & 10.84 & 0.55 & 0.00 & $\mathbf{9 6 . 7 9}$ & 0.05 \\
MChl & 0.376 & 0.137 & 3.61 & 9.60 & 0.36 & $\mathbf{2 6 . 3 5}$ & $\mathbf{1 . 0 2}$
\end{tabular}

Naphthalene (NAP), Acenaphthalene (ACP), Acenaphthene (ACE) and Fluorene (FL), Phenanthrene (PHE), Anthracene (ANT), Fluoranthene (FLU), Pyrene (PYR), Benzo(a)anthracene [B(a)ANT], Chrysene (CHY), Benzo(b)fluoranthene [B(a)FLU], Benzo(a)pyrene B(a)PYR; 3-Methylcholanthrene MChl; Benzo(e)pyrene B(e)PYR Benzo(k)fluaranthene B(k)FLU Benzo(k)fluaranthene B(b)FLU; Benzo(j)fluaranthene B(j)FLU; Indeno(1,2,3-cd)pyrene [IN(cd)PYR], Dibenzo(a,h)anthracene [Di(ah)ANT] and Benzo(g,h,i)perylene [B(ghi)PYL. Dibenzo(a,l)pyrene DiB(ai)PYR; . Dibenzo(a,l)pyrene DiB(ah)PYR. BAFi/w= intestine-water bioaccumulation factor, $\mathrm{BSAFi} / \mathrm{w}=$ intestine-water biota-sediment bioaccumulation factor, $\mathrm{BAF} / \mathrm{i}=$ parasiteintestine bioaccumulation. Emboldened Fig.s indicate significant difference (=or $>1)$.

There was a significant positive correlation between bioaccumulation factors of PAHs from water to the intestine of Gymnarchus niloticus. A highly significant positive correlation occurred between bioaccumulation factors of PAHs and biotasediment accumulation factors, from water and sediment respectively to the intestine of the fish. Although not significant, the bioaccumulation factor of PAHs from intestine to the enteric parasite showed negative relationship with the concentrations of PAHs in the fish intestine, and the accumulation factors in the intestine relative to water and sediment (Table 4). 
Table 4: Correlation relation among PAH concentrations in fish intestine and bioaccumulation indices

\begin{tabular}{lcccc}
\hline & Intestine & $\mathrm{BAFi} / \mathrm{w}$ & $\mathrm{BSAFi} / \mathrm{s}$ & $\mathrm{BAFp} / \mathrm{i}$ \\
\hline Intestine & 1 & & & \\
$\mathrm{BAFi} / \mathrm{w}$ & $\mathbf{0 . 5 2 1 1 7 6}$ & 1 & & \\
$\mathrm{BSAFi} / \mathrm{s}$ & 0.403411 & $\mathbf{0 . 9 2 0 2 6 5}$ & 1 & \\
$\mathrm{BAFp} / \mathrm{i}$ & -0.1151 & -0.13057 & -0.13194 & 1 \\
\hline BAFi/w= bioaccumulation factor of PAH from water to intestine \\
BSAFi/s= biota-sediment accumulation factor of PAH from sediment to intestine \\
BAFp/i= bioaccumulation factor of PAH from intestine to parasite Emboldened \\
Fig.s indicate significant difference $(\mathrm{p}<0.05)$
\end{tabular}

However, the relationship between the intestinal concentrations of PAHs to their bioaccumulation factors from the intestine to the parasite using a regression analysis (Fig. 2) indicated an insignificant regression of the PAHs contamination in the fish intestine on the accumulation capacity $\left(F(1,21)=0.2, p>0.05, R^{2}=0.01\right)$.

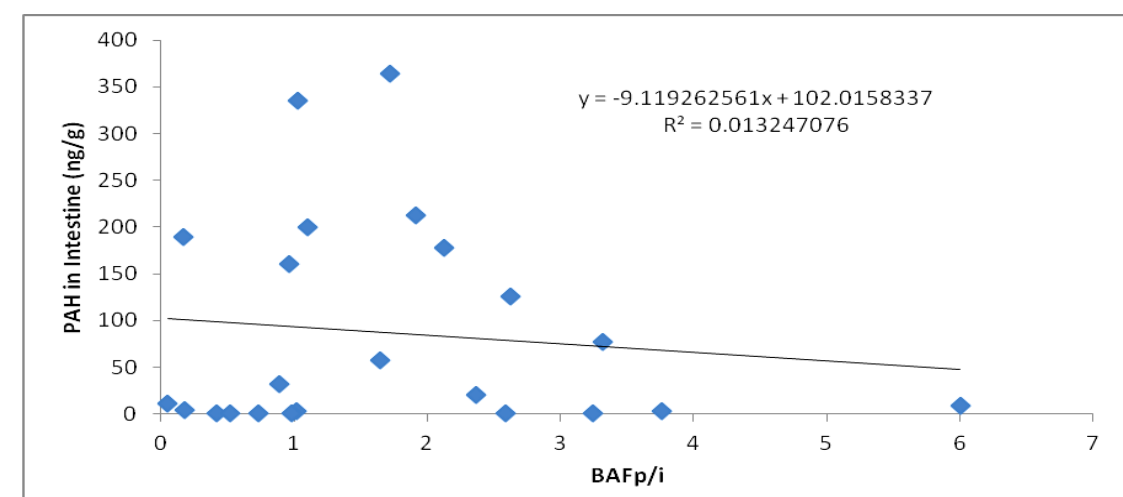

Fig. 2: Regression analysis of PAH concentration in tish intestıne on bioaccumulation tactor of PAH from intestine into fish parasite

\section{Biochemical biomarkers}

Reduced glutathione (GSH) in the infected intestine and parasite were significantly lower than the levels in the uninfected fish (Fig. 3). A similar trend occurred in the super oxide dismutase (SOD) (Fig. 4). However, the level of catalase (CAT) in the parasite competed closely with the levels in the intestine of the infected fish (Fig. 5).

Conversely, MDA levels in the intestine of the uninfected fish was significantly far higher $(\mathrm{p}<0.01)$ than the concentrations in the infected fish and their enteric parasite, $R$. brasiliensis (Fig. 6).

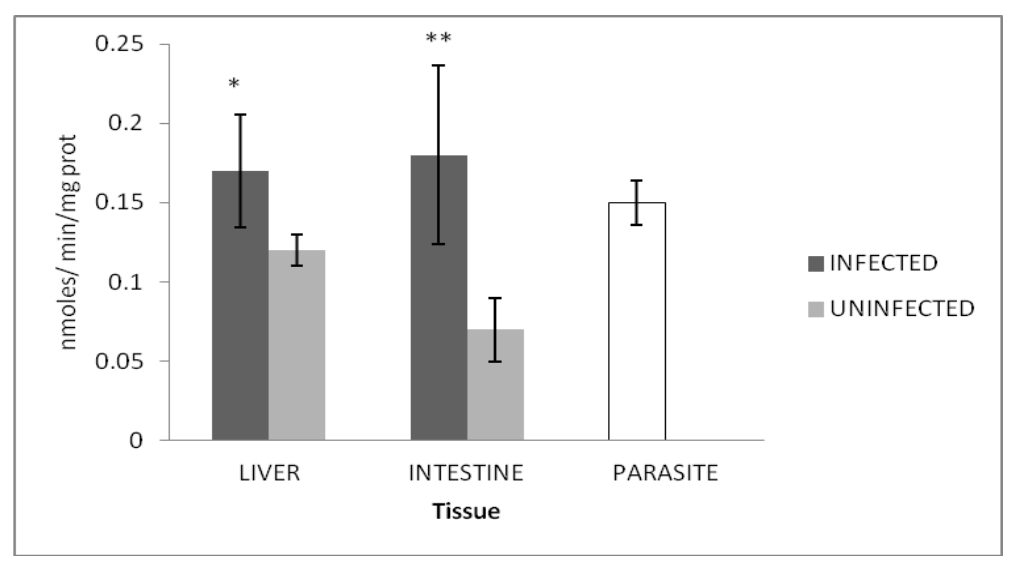

Fig. 3: Levels of GSH in the liver and intestine of uninfected fish, infected fish, and the parasite. * Significant difference $(\mathrm{p}<0.05), * *(\mathrm{p}<0.01)$. Sample size $(\mathrm{N})=10$. 


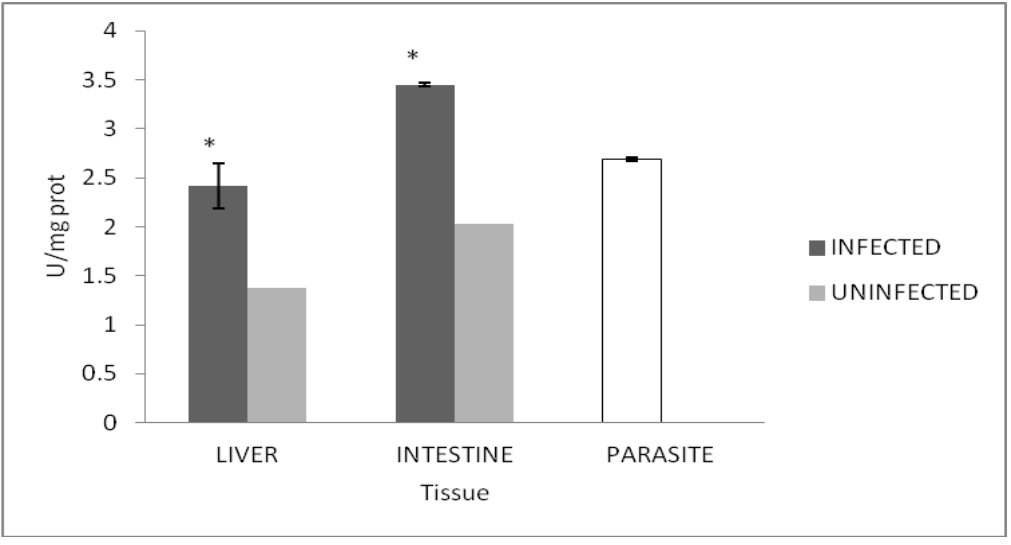

Fig. 4: Levels of SOD in the liver and intestine of uninfected fish, infected fish, and the parasite. * Significant difference $(\mathrm{p}<0.05), * *(\mathrm{p}<0.01)$. Sample size $(\mathrm{N})=10$.

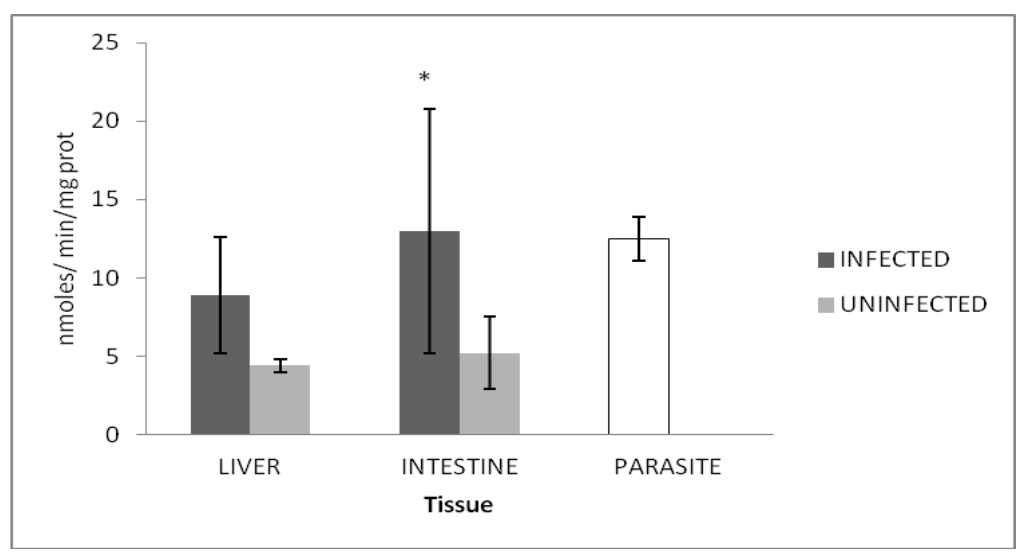

Fig. 5: Levels of CAT in the liver and intestine of uninfected fish, infected fish, and the parasite. * Significant difference $(\mathrm{p}<0.05), * *(\mathrm{p}<0.01)$. Sample size $(\mathrm{N})=10$.

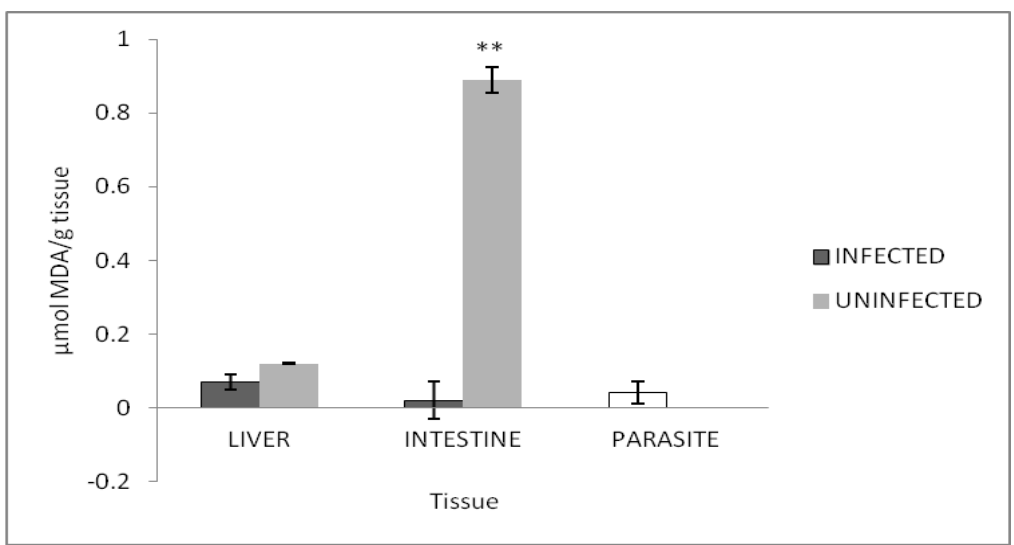

Fig. 6: Levels of MDA in the liver and intestine of uninfected fish, infected fish, and the parasite. * Significant difference $(\mathrm{p}<0.05), * *(\mathrm{p}<0.01)$. Sample size $(\mathrm{N})=10$. 


\section{DISCUSSION}

The disparity between the observed sex ratio (1:9; female to male) and the expected $(2: 1)$ may be due to inadequacies in the capture methods adopted by the artisanal fishermen. The current observed inverse relationship between fish standard length and parasite prevalence is at variance with the observation of Akinsanya et al. (2019) who observed proportionate relationship. Although the total parasite prevalence of $8.75 \%$ was quite too low to be of significant parasitological impact on the fish, the parasites however exhibited some depuration tendencies on the fish. They also showed the highest accumulation capacity for PAH congeners among the analyzed environmental media. This is evident in the significant bioaccumulation factors of most PAH congeners from the fish intestine to the parasite and the sequence of accumulation in the environmental matrices which was parasite> intestine> sediment> water.

Comparing the current observations with previous studies on other rivers such as Rivers Blythe, Tyne, Wear, and Tees in North East England. The total PAH concentrations in sediments of Lekki Lagoon were in excess of 10,000 ng/g dry weights (Woodhead et al., 1999). Total concentrations of 17 PAH congeners ranging from $107 \mathrm{ng} / \mathrm{g}$ to $1,701 \mathrm{ng} / \mathrm{g}$ were reported for surface sediments of rivers and an estuary in Shanghai, China (Liu et al., 2008). The parasite had the highest concentrations of the 2-3 rings PAH congeners which include Acenaphthalene (ACP) and Acenaphthene (ACE) Naphthalene (NAP), Fluorene (FL), and Phenanthrene (PHE) with a total sum of congeners concentrations of $105.87 \mathrm{ng} / \mathrm{g}$ followed by the intestine $(31.34 \mathrm{ng} / \mathrm{g})$, sediment $(1.592 \mathrm{ng} / \mathrm{g})$, and then water $(1.433 \mathrm{ng} / \mathrm{g})$. The nematode parasite also had the highest concentrations of the 4-6 PAH rings congeners, with a total sum of congener concentrations of $2890.01 \mathrm{ng} / \mathrm{g}$ followed by the intestine, $1956.09 \mathrm{ng} / \mathrm{g}$, sediment $(12.216 \mathrm{ng} / \mathrm{g})$ and then water $(4.457 \mathrm{ng} / \mathrm{g})$.

The total concentrations of $23 \mathrm{PAH}$ congeners and potential carcinogenic PAHs in sediments from the inter-tidal areas of Dares Salaam, Tanzania ranged from 78 to $25,000 \mathrm{ng} / \mathrm{g}$ and 5 to $11,000 \mathrm{ng} / \mathrm{g}$, respectively (Gaspare et al., 2009). Globally, PAHs concentrations ranging from 1 to $760,000 \mathrm{ng} / \mathrm{g}$, and with modal concentrations of 1,000 to 10,000 have been reported for rivers, estuaries, harbors, and coastal areas polluted with PAHs (Zakaria et al., 2002). Among the congeners, Benzo(a)pyrene had the highest concentration in the water medium in the Lagoon. Some properties of Benzo(a)pyrene such as high toxicity, low sensitivity to photo-oxidation, high persistence in water and low molecular weight (Woodhead et al., 1999), makes it one of the most studied congeners.

PAHs composition in sediments and water may be used to characterize and identify the sources of contamination by employing multivariate statistical tools or diagnostic ratios between specific compounds (Baumard et al., 1998; Zakaria et al., 2002; Ma et al., 2005; Liu et al., 2008). The main anthropogenic sources of PAHs include the incomplete combustion of fossil fuels and other organic substances (pyrogenic) and also as components of crude oil and its refined products (petrogenic). The ratios of Phen/Ant and Flu/Pyr have been used extensively to distinguish petrogenic and pyrogenic sources (Baumard et al., 1998). In this study, the ratio of PHE/ANT, FL/PYR and ACE/FLU in the sediment was 1.820, 29.667, and 4.33 respectively.

These source indices ( $>1.0)$ indicate a petrogenic source. Contamination of the aquatic ecosystem by petrogenic PAHs was earlier reported by Doherty and Otitoloju 
(2016). PAHs in sediments enter the fish by partitioning from the organic fraction of sediment particles into pore water, from where it proceeds to the tissues of the fish.

The trend in water medium was almost the reverse of the trend in the sediment. The inverse trend explains the differential dynamics of hydrophilicity and lipophilicity in conjunction with the repository nature of the bottom sediment. Furthermore, contaminated bottom sediment may re-pollute the overlying water column through natural processes which generate water current (Peng et al., 2014) thereby posing future ecological and health challenges (Chau, et al., 2005; Cachot et al., 2006; Tobiszewski and Namieśnik, 2012; Lindgren et al., 2014). Re-pollution is however countered by natural recuperative processes such as dispersion, weathering, evaporation, dissolution, and biodegradation (Neff et al., 2005).

A major feeding habit of $G$. niloticus is primarily hunting for aquatic macrofauna (Bailey, 1994) which are notable for accumulation of contaminants. The G. niloticus is quite susceptible to exposure to PAHs in the sediment through ingestion and absorption. Hydrocarbons associated with sediment particulates are considered significantly bioavailable to the demersal fish. Bioaccumulation of particle-associated hydrocarbons by direct contact with external body surfaces of the fish or by ingestion of the particles involves an intermediate phase in which the hydrocarbons desorb from the particle into the aqueous phase and then are absorbed across the fish epithelium (Di Toro et al., 1991; 2000; Neff, 2002; Hansen et al., 2003). Hydrocarbons associated with sediment particles must partition from the sediment particles into solution before they can move across biological membranes and be taken up by the fish. As expected, the LMW PAHs exhibited higher solubility in the water than the HMW PAHs. For PAHs to accumulate in the lipid of the fish successfully, sufficient amount have to enter the pore water to allow rapid partition into the permeable membranes or across the gut epithelium when particles and pore water are ingested. In the fish gut, PAH solubility is enhanced by surfactants and enzymes secreted by the fish (Mayer et al., 1996). The biochemical increases the absorption capacity of the fish gut thereby aggravating exposure of the animal.

The carcinogenic health risks posed by both the low and high molecular weight PAHs (0.027 and 0.476 respectively) were insignificant; hence the fish may not pose toxicological threats to consumers. Although the PAHs in the Lagoon exhibited no significant ecological risk, it was however greatly adsorbed on the bottom sediment (particularly the HMW PAHs). Law and Klungsoyr (2000) earlier posited that PAHs are notable for high affinity for sediments and as such they may pose carcinogenic risk to human in the future.

Higher lipohilicity of HMW PAHs than the LMW observed in the study conforms to previous observations which explained an inverse relationship between PAH solubility and their molecular weights (MDEPORS, 2007). Although most of the PAH congeners were of relatively low concentrations in the sediment as at the time of this investigation, the high sorption coefficient detected in the aquatic habitat is a prognosis of an abrupt rise in the levels of PAHs in the sediment thereby resulting in future ecophysiological toxicities. This therefore necessitates regular biomonitoring of the aquatic habitat to keep the sediment PAH levels in constant check. Re-pollution of the overlying water column by the bottom sediment is much more likely with the LMW PAHs than the HMW. Asides water movement which mediates the re-pollution process, other natural processes which rather sequester the levels of PAHs in aquatic habitat include dispersal, weathering, evaporation, dissolution, and biodegradation (Neff et al., 1994). Baumard et al. (1999) also 
suggested that factors such as organic matter composition, $\mathrm{pH}$ and temperature may also play vital roles in bioavailability of PAHs.

Most of the PAH congeners were highly accumulated from the sediment and aqueous phase into the intestine of the fish. Although insignificant regression and correlation between the PAH levels in the fish intestine and the accumulation by the enteric parasite suggest that PAHs were poorly depurated by the enteric parasite, Raphidascaroides brasiliensis in the fish. Better depuration capacities are feasible at higher parasite intensities (Akinsanya et al., 2019). Greater immunosuppression than depuration of trace metals was observed in green frog Pelophylax synkl infected with parasitic helmiths (De Donato et al., 2017). De Donato et al. (2017) further explained the immunosuppressive tendencies of xenobiotics which may culminate in parasitological susceptibility. Although knowledge on the complex interactions among toxicants, parasites and host is not sufficient, current study however suggests possibility of depurative niche of Raphidascaroides brasiliensis without devastating parasitological implications. Raphidascaroides brasiliensis may mediate homeostasis between health implications and bioaccumulation of PAHs in G. niloticus.

Oxidative stress in the uninfected fish was characterized by significantly lower levels of SOD, and CAT. Furthermore, the level of MDA detected in the uninfected fish was close to the levels detected in the enteric parasite. Vadhva \& Hasan (1986) earlier observed that the level of MDA content increased dose-dependently in stinging catfish (Heteropneustes fossilis) exposed to dichlorvos. Hai et al. (1997) also observed that CAT activity in the liver, GSH level in the brain, muscle and heart; SOD level in liver, and MDA in the brain of brown bullhead (Ictalurus nebulosus) reduced after 24 hours of exposure to PAHs.

Observations from this study in the light of previous discoveries suggest that absence of depurative effects of Raphidascaroides brasiliensis in uninfected $G$. niloticus may have contributed to the toxicity effects.

\section{CONCLUSION}

The study presented evidences of contamination of the sediment in Lekki Lagoon by industrial petrogenic effluents, which requires constant biomonitoring to forestall pollution of the lagoon. Depurative potential of Raphidascaroides brasiliensis may be attained at higher infection rates. To this end, study on significant depuration at minimal parasite intensity is recommended.

\section{REFERENCES}

Adeyemi, D.; Ukpo, G.; Anyakora, C. and Uyimadu, J. P. (2009). Polychlorinated biphenyl in fish samples from Lagos Lagoon, Nigeria. African Journal of Biotechnology, 8(12):2811- 2815

Ake Assi, Y.; Biego, G. H. M.; Sess, A. D.; Koffi, K. M.; Kouame, P.; Bonfoh, B.; Akpagni, H. and Ausset, E. (2012). Validation of a Method for the Quantification of Polycyclic Aromatic Hydrocarbons in Fish. European Journal of Scientific Research ISSN 1450-216X .74(1): 69-78

Akinsanya, B.; Hassan A.A. and Adeogun, A.O. (2008). Gastrointestinal Helminth Parasites of the fish Synodontis clarias (Siluriformes: Mochokidae) from Lekki 
Lagoon, Lagos, Nigeria, accessed at http://www.biologia. ucr.ac.cr/rbt/ attachments/volumes/vol56-4/ on 26/08/2010.

Akinsanya, B.; Ukwa, U.D. and Hassan, A.A. (2014). Effect of Host Condition on intestinal parasite load and prevalence in Malapterurus electricus, Gmelin 1789, (Siluriformes: Malapteridae) In Lekki Lagoon, Lagos, Nigeria. Nigeria Journal of Parasitology, 35: 59-64.

Akinsanya M. A.; Goh J. K.; Lim S. P. and Tinga A. S. Y. (2015). Metagenomics study of endophytic bacteria in Aloevera using next-generation technology. Genom. Data, 6: 159-163. 10.1016/j.gdata.2015.09.004.

Akinsanya B. and Adekogbe A. F. (2017). Parasitic Helminth Fauna and Heavy Metals Analysis in Macrobrachium macrobranchion and Macrobrachium vollenhovenii From Lekki Lagoon, Lagos, Nigeria. Egypt. Acad. J. Biolog. Sci., 9(1): 71- 88

Akinsanya, B.; Adebusayo, S. A.; Alinson, T. and ukwa, U. D. (2018). Bioaccumulation of polycyclic hydrocarbons, hitopathological alterations, and parasite-fauna in bentho-pelagic host from Snake Island, Lagos, Nigeria. The Journal of Basic and Applied Zoology, 79:40

Akinsanya, B.; Isibor, P. O.; Kuton, M. P.; Saliu, J. K. and Dada, E. O. (2019). Aspidogastrea africanus Infections, comparative assessment of BTEX and heavy metals Bioaccumulation, and histopathological alterations as biomarker response in Chrysichthyes nigrodigitatus (Lacépède, 1803) of Lekki Lagoon, Nigeria. Scientific African 3(2019):1-10

Albert, L.; Juhasz, M. and Ravendra, C. (2000). Bioremediation of high molecular weight polycyclic aromatic hydrocarbons: a review of the microbial degradation of benzo[a]pyrene. International Biodeterioration \& Biodegradation, 45: 57-88.

Amadi, A.A.; Dickson, A. and Maate, G.O. (1993). Remediation of oil polluted soil. Effect of organic and inorganic nutrient supplement on performance of maize (Zea mays L). Water Air Soil Pollution, 66: 59-76.

Amaeze, N. H.; Adeyemi, R. O. and Adebesin, A. O. (2015). Oxidative stress, heat shock protein and histopathological effects in the gills of African catfish, Clarius garienpinus induced by bridge runoffs. Environmental Monitoring and Assessment, 187: 172.

Anyakora, C. A.; Ogbeche, Ogbeche, K. A.; Unyimadu, J.; Olayinka, K.; Alani, R. and Alao, B. (2004). Determination of polynuclear aromatic hydrocarbons in water samples of the Lagos lagoon. Nigerian Journal Pharmacy. 35:35-39

Association Francaise De Normalisation (1998). Analyse des produits agricoles et alimentaires: Procédure de validation intralaboratoire d'une méthode alternative par rapport à une méthode de référence. Paris : Edition AFNOR. 40 p.

Ayoade, A.A.; Mustapha A.T. and Oguntolu, M.O. (2013). Length-Weight Relationship and Diet of Gymnarchus niloticus in a Tropical Man-Made Lake, Southwestern Nigeria. Nigerian Journal of Fisheries 10 (1 \&2):606-612.

Bailey, R.G. (1994). Guide to the fishes of the River Nile in the Republic of the Sudan. J. Nat. Hist. 28:937-970.

Baumard, P.; Budzinski, H.; Michon, Q.; Garrigues, P.; Burgeot, T. and Bellocq, J. (1998). Origin and bioavailability of PAHs in the Mediterranean sea from mussel and sediment records. Estuar. Coast. Shelf S., 47: 77-90.

Buege, J. A. and Aust, S. (1978). Microsomal Lipid Peroxidation. Methods in Enzymology, 52: 302-310. 
Butler, J. L. (1992). Collection and preservation of material for otolith analysis,. InD. K. Stevenson and S. E. Campana [cd.] Otolith microstructure examination and analysis. Can. Spec. Publ. Fish. Aquat.Sel., 117: 13-17.

Cachot, J.; Geffard, O.; Augagneur, S.; Lacroix, S.; Le Menach, K.; Peluhet, L.; Couteau, J.; Denier, X.; Devier, M.H.; Pottier, D. and Budzinski, H. (2006). Evidence of genotoxicity related to high PAH content of sediments in the upper part of the Seine estuary (Normandy, France). Aquat Toxicol 79(3):257-267.

Camargo, M. C. R. and Toledo, M. C. F. (2002). Polycyclic aromatic hydrocarbon contamination in different commodity groups. Brazilian J. of Food Technol., 5: $19-26$.

Central Intelligence Agency (CIA). (2016). World Factbook. Pp 17.

Chau, A.; Heinz, K. M. and Davies Jr., F. T. (2005). Influences of fertilization on Aphis gossypii and insecticide usage. 129 (3): 176-184.

Colombo, J.; Cappelletti, N.; Barreda, A.; Migoya, M. C. and Skorupka, C. N. (2005). Vertical fluxes and accumulation of PCBs in coastal sediments of the Río de la Plata estuary, Argentina. Chemosphere, 61, 1345-1357.

Dobrinas, S.; Birghila, S. and Coatu, V. (2008). Assessment of polycyclic aromatic hydrocarbons in honey and propolis produced from various flowering trees and plants in Romania. J. of Food Composition and Analysis, 21(1): 71-77.

Doherty, V. F. and Otitoloju, A. A. (2016). Occurrence and distribution of monocyclic aromatic hydrocarbons (BTEX) and the impact on macrobenthic community structure in Lagos Lagoon, Nigeria. Environ Monit Assess, 188: 571

Egborge, A. B. M. (1991). Industrialization and heavy metal Pollution in Warri River. $32^{\text {nd }}$ Inaugural lecture, University of Benin, Benin City, Nigeria. 32pp.

Ellman, G.L. (1959). Tissue sulfhydryl groups. Archives of Biochemistry and Biophysics, 82, 70-77. doi:10.1016/0003-9861(59)90090-6

Enuneku, A. A. and Ilegomah, B. O. (2015). Concentrations of BTEX in Shrimps of Ovwian-Udu River, Warri, Delta State, Nigeria and human health implications. European International Journal of Science and Technology. 4(7):32-40.

Federal Environmental Protection Agency (FEPA) (2003). Guidelines and Standards for Environmental pollution control in Nigeria. Pp 420.

Gaspare, L.; Machiwa, J. F.; Mdachi, S. J. M.; Streck, G. and Brack, W. (2009). Polycyclic aromatic hydrocarbon (PAH) contamination of surface sediments and oysters from the inter-tidal areas of Dar es Salaam, Tanzania. Environ. Pollut., 157: $24-34$.

Hites, R.A.; Laflamme, R.E. and Windsor Jr., J.G. (1980). Polycyclic aromatic hydrocarbons in an anoxic sediment core from the Pettaquamscutt River (Rhode Island, USA). Geochim. Cosmochim. Acta., 44: 873-878

Humason, A.W. and Gadbois, D.F. (1982). Determination of polynuclear aromatic hydrocarbons in the New York bight area. Bulletin of Environmental Contamination and Toxicology. 29: 645-650.

IARC (1983). IARC Monographs on the Evaluation of the Carcinogenic Risk of Chemicals to Humans, Vol. 32,Polynuclear Aromatic Compounds, Part 1, Chemical, Environmental and Experimental Data, Lyon. 239-245pp.

Imlay, J.A. (2003). Pathways of oxidative damage. Annual Review of Microbiology, 57: $395-418$. 
International Standard Organisation (ISO) (2004). Corps gras d'origine animale et végétale - Détermination des hydrocarbures aromatiques polycycliques. Geneve : ISO $15753.21 \mathrm{p}$.

Isibor, P. O. and Oluowo, E. F. (2016). Evaluation of some heavy metals and total petroleum hydrocarbon in water and Palaemonid Shrimps (Macrobrachium vollenhovenii) of Egbokodo River, Warri, Delta State, Nigeria. Journal of Applied Life Sciences International. 6 (4):1-12. DOI: 10.9734/JALSI/2016/27148.

Isibor, P. O. and Imoobe, T. O. T. (2017). Comparative Analysis of Contaminability between Clarias gariepinus and Tilapia mariae. Annual Research and Review in Biology. 16(5): 1- 14. DOI: 10.9734/ARRB/2017/34920.

Knutzen, J. and Sortland, B. (1982). Polycyclic aromatic hydrocarbons (PAH) in some algae and invertebrates from moderately polluted parts of the coast of Norway. Water Resources, 16: 421-428.

Law, R.J. and Klungsoyr, J. (2000). The analysis of polycyclic aromatic hydrocarbons in marine samples. Int. J. Environ. Pollution, 13: 262-283.

Lindgren, J.F.; Hassellöv, I.M. and Dahllöf, I. (2014). PAH effects on meio- and microbial benthic communities strongly depend on bioavailability. Aquat Toxicol. 146:230-238. doi: 10.1016/j.aquatox.2013.11.013.

Liu, Y.; Chen, L.; Jianfu, Z.; Qinghui, H.; Zhiliong, Z. and Hongwen, G. (2008). Distribution and source of polycyclic aromatic hydrocarbons in surface sediments of rivers and an estuary in Shanghai. China Environ. Pollut., 154: 298-305.

Lu, P.Y.; Metcalf, R. L.; Plummer, N. and Mandrel, D. (1999). The environmental fate of three carcinogens, benzo(a)pyrene, benzidine, and vinyl chloride evaluated in laboratory model ecosystems. Arch. Environ. Contam. Toxicol., 6: 129-142.

Ma, L. L.; Chu, S. G.; Wang, X. T.; Cheng, H. X.; Liu, X. F. and Xu, X. B. (2005). Polycyclic aromatic hydrocarbons in the surface soils from outskirts of Beijing, China. Chemosphere, 58: 1355-1363.

Massachusetts Department of Environmental Protection Office of Research and Standard (MDEPORS). (2007). Sediment toxicity of PAH fractions. Battelle, 897 Washington Street, Duxbury, MA 02332 Pp 89.

McCarty, L.S.; Mackay, D.; Smith, A.D.; Ozburn, G.W. and Dixon, D.G. (1993). Residue-based interpretation of toxicity and bioconcentration QSARs from aquatic bioassays: polar narcotic organics. Ecotoxicol. Environ. Saf. 25:253270.s

Neff, J.M.; Stout, S.A. and Gunster, D.G. (2005). Ecological risk assessment of PAHs in sediments. Identifying sources and toxicity. Integr. Environ. Assess. Manage. $1(1): 22-33$.

NRC (National Research Council) (1983). Risk Assessment in the Federal Government: Managing the Process. Washington, DC: National Academy Press.

Pena-Llopis, S.; Ferrando, M.D. and Pena, J.B. (2003). Increased recovery of brain acetylcholinesterase activity in dichlorvos-intoxicated european eels Anguilla anguilla by bath treatment with $\mathrm{N}$-acetylcysteine. Diseases of Aquatic Organisms, 55: 237-245.

Plaza-Bolanos, P.; Frenich, A. G. and Vidal, J. L. M. (2010). Polycyclic aromatic hydrocarbons in food and beverages. Analytical methods and trends. J. of Chromatogr., 1217: 6303 - 6326. 
Peng, S.; Zhou, K.; Wang, W.; Gao, Z.; Dong, Y. and Liu, Q. (2014). High-resolution crystal structure reveals a HEPN domain at the C-terminal region of $\mathrm{S}$. cerevisiae RNA endonuclease Swt1. Biochem Biophys Res Commun 453(4):826-32

Poulin, B. (1992). Determinants of host-specificity in parasites of freshwater fishes. Int. J. Parasitol., 22: 753-761.

Quinlan, T. R.; Marsh, J. P.; Janssen, Y. M. W.; Borm, P. A. and Mossman, B. T. (1994). Oxygen radicals and asbestos-mediated disease. Environ Health Perspect 102(suppl 10):107-110.

Redondo, J.M. and Platonov, A.K. (2009). Self-similar distribution of oil spills in European coastal waters. Environ. Res. Lett., 4: 14008.

Robert, A.; Kanaly, M. and Shigeaki, H. (2014). Bench scale evaluation of alternative biological treatment process for the remediation of pentachlorophenol and creosote contaminated materials: slurry phase bioremediation. Environmental Science and Technology, 25: 1055-1061.

Simko, P. (2002). Determination of polycyclic aromatic hydrocarbons in smoked meat products and smoke flavouring food additives. J. of Chromatogr., 770: 318.

Siroka, Z.; Krijt., J.; Randak., T.; Svobodova, Z.; Peskova, G.; Fuksa, J.; Hajslova, J.; Jarkovsky, J. and Janska, M. (2005). Organic Pollutant Contamination of River Elbe as assessed by biochemical markers. Acta Vet Brno 74:293303.

Smith, K. L. and Guentzel, J. L. (2010). Mercury concentrations and omega-3 fatty acids in fish and shrimp: Preferential consumption for maximum health benefits. Marine Pollution Bulletin, 60 (9): 1615-1618.

Soares, M. R. and Alleoni, L. R. F. (2006). Distribution coefficient (KD) of heavy metals in Brazillian soils. 18tth World Congress of Soil Sciences, Philadelphia, USA. Pp 134.

Sures, B. (2007). Host-parasite interactions from an ecotoxicological perspective. Parassitologia, 49, 173-176.

Stankovic, D.; Krstic, B. and Nikolic, N. (2011). Effect of traffic on the soil contamination with polycyclic aromatic hydrocarbons (PAHs). Biotechnol. Biotechnol. Equipment, 22(Issue 2): 736-741.

Sun, M., and Zigman, S. (1978). An improved Spectrophotomeric assay for Superoxide dismutase based on epinephrine autoxidation.. Analytical Biochemistry, 906: 81-89.

Sures, B. (2007). Host-parasite interactions from an ecotoxicological perspective. Parassitologia, 49, 173-176.

Tobiszewski, M. and Namieśnik, J. (2012). PAH diagnostic ratios for the identification of pollution emission sources. Environmental Pollution162 (10), $110-119$.

Twiss, M.R.; Granier L.; Lafrance P. and Campbell, P.G.C. (1999). Bioaccumulation of 2,29,5,59- tetrachlorobiphenyl and pyrene by picoplankton (Synechococcus leopoliensis, Cyanophyceae): influence of variable humic acid concentrations and pH. Environmental Toxicology and Chemistry, 18: 2063-2069.

United States Environmental Protection Agency (USEPA). (1990). Determination of Polycyclic Aromatic Hydrocarbons in Drinking Water by LiquidSolid Extration and HPLC with Coupled Ultraviolet and Fluorescence Detection. Method 550.1, 1990, EPA Environmental Monitoring Systems Laboratory, Office of Research and Development, Cincinnati, Ohio 45268. 
Vadhva, P., and Hasan, M. (1986). Organophosphate dichlorvos induced dose-related differential alterations in lipid levels and lipid peroxidation in various regions of the fish brain and spinal cord. J. Environ Sci. Health, 21: 413-424.

Wakeham, S.G.; Schaffner, C. and Giger, W. (1980). Polycyclic aromatic hydrocarbons in recent lake sediments- I. Compounds having anthropogenic origins. Geochim. Cosmo. Acta., 44: 403-413.

Wenzl, T.; Simon, R.; Kleiner, J. and Anklam, E. (2006). Analytical methods for polycyclic aromatic hydrocarbons (PAHs) in food and the environment. African Journal of Food Sci., 87: 45-65.

Woodhead, R. J.; Law, R. J. and Matthiessen, P. (1999). Polycyclic aromatic hydrocarbons in surface sediments around England and Wales, and their possible biological significance. Marine Pollut. Bull., 38: 773-790.

World Health Organisation (WHO) (2001). Environmental Health Criteria 222. Biomarkers in risk assessment: validity and validation. Geneva, Switzerland: World Health Organization.

WHO (2005). Polynuclear aromatic hydrocarbons in Drinking-water. Background document for development of WHO Guidelines for Drinking-water Quality, World Health Organisation., Geneva.

Xing, Y.; Lu, Y.; Dawson, R. W.; Shi, Y.; Zhang, H. and Wang, T. (2005). A spatial temporal assessment of pollution from PCBs in China. Chemosphere, 60, 731739.

Zakaria, M.P.; Takada, H.; Tsutsumi, S.; Ohno, K.; Yamada, J.; Kound, E. and Kumata, H. (2002). L.ok,Distribution polycyclic aromatic hydrocarbons (PAHs) in rivers and estuaries in Malaysia: a widespread input of petrogenic PAHs. Environ, Sci. Technol., 36: 1907-1918. 